Brit. J. prev. soc. Med. (1963), 17, 172-176

\title{
ANALYSIS OF ADMISSIONS TO A CASUALTY WARD
}

\author{
BY \\ MALCOLM C. PIKE, * DAVID M. PROCTOR, AND JOHN M. WYLLIE
}

From the Department of Statistics, Aberdeen University, and the Casualty Department, Aberdeen Royal Infirmary

General hospital wards have to make provision not only for emergency cases but also for patients admitted from waiting lists. Admission of emergency cases and especially of short-stay emergencies use many of their beds and retards the admission of list cases. Short-stay emergencies do not require highly specialized treatment and it is wasteful of facilities in major units to reserve beds for them there. Such patients, however, must be admitted for surveillance or short-term treatment or even because of geographic or social considerations.

Since 1958 a short-stay ward has been part of the Casualty Department of Aberdeen Royal Infirmary, and this paper describes fluctuations in the admission rate and number of beds occupied. It is interesting that the fluctuations can be very simply described mathematically. The random nature of emergency admissions makes this possible and there are no elective admissions to affect the situation. Our findings provide a method of predicting the number of beds actually required to allow for random fluctuations.

The hospital centre for the north-eastern region of Scotland is in Aberdeen where there are Casualty Departments at the Royal Infirmary and at the Royal Aberdeen Hospital for Sick Children. The population served is approximately 250,000 , and of that number about 190,000 live in the City of Aberdeen.

The Casualty Department of the Aberdeen Royal Infirmary is situated at Woolmanhill about 2 miles from the main hospital at Foresterhill. It maintains a 24-hour service and is staffed by full-time Casualty Officers (one Registrar, one Junior Hospital Medical Officer, and three House Officers) with a Senior Casualty Officer of Senior Hospital Medical Officer

* Now at the M.R.C. Statistical Research Unit, University College Hospital Medical School, London. status in control. It has its own $x$ ray department with full-time radiographers by day and a radiographer living in at night.

There is a short-stay ward at Woolmanhill with ten beds available for the admission of patients seen in the Casualty Department. Admission policy is to admit only patients who are likely to be fit for discharge in 3 days' time. It is accepted that a patient may be transferred to a bed in the main hospital within that time if his condition requires it or at the end of that time if more prolonged treatment or observation is considered necessary. In a few instances the 3-day limit is not strictly observed; the extended time is usually due to social considerations but occasionally patients are detained for one or two days longer in order to complete treatment which does not warrant transfer for such a short period. Of the ten beds, five are normally in the male and four in the female ward and one is in a single room. Fluctuations in admissions of men and women sometimes necessitate alteration in this distribution of beds between the wards.

\section{Selection of Patients}

In 1961 a total of 30,877 new patients attended the Casualty Department. Of these $760(2 \cdot 5$ per cent.) were immediately referred to other Departments. Many of these patients were severely injured. A further 733 patients were admitted to the short-stay ward; however, ninety of these were not discharged home but were transferred to other wards. Tables I and II (opposite) classify the patients by diagnosis.

The number of patients transferred is not necessarily an indication of incorrect assessment of the cases when first seen. For example, all 99 cases of drug overdose were seen by a psychiatrist and the eighteen who were transferred to a mental hospital are an indication of the proportion of serious 
TABLE I

PATIENTS IMMEDIATELY TRANSFERRED TO OTHER WARDS, BY DIAGNOSIS

(1 Jan. to 31 Dec., 1961)

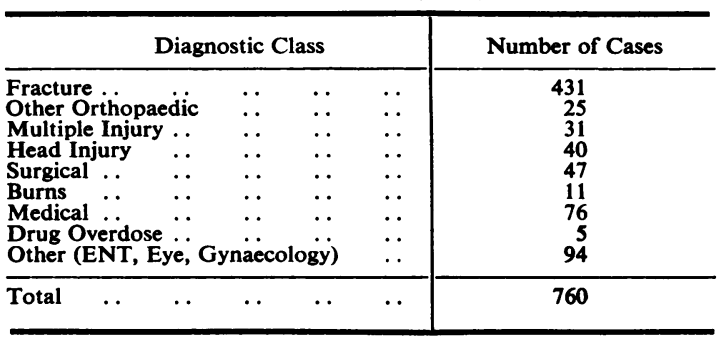

TABLE II

PATIENTS DETAINED IN SHORT-STAY WARD, BY DIAGNOSIS

(1 Jan. to 31 Dec., 1961)

\begin{tabular}{|c|c|c|c|}
\hline Diagnostic Class & $\begin{array}{l}\text { Number } \\
\text { (Percentage } \\
\text { of males) }\end{array}$ & $\begin{array}{l}\text { Average } \\
\text { Duration of } \\
\text { Stay (days) }\end{array}$ & $\begin{array}{l}\text { Number } \\
\text { Subsequently } \\
\text { Transferred }\end{array}$ \\
\hline 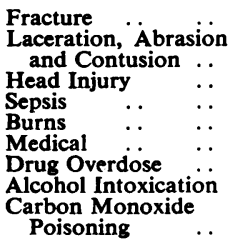 & $\begin{aligned} 162 & (63) \\
119 & (64) \\
203 & (67) \\
39 & (56) \\
17 & (59) \\
55 & (69) \\
99 & (30) \\
32 & (89) \\
7 & (11)\end{aligned}$ & $\begin{array}{l}1 \cdot 8 \\
1 \cdot 7 \\
1 \cdot 5 \\
2 \cdot 3 \\
2 \cdot 2 \\
1 \cdot 5 \\
1 \cdot 2 \\
1 \cdot 4 \\
1 \cdot 3\end{array}$ & $\begin{array}{r}31 \\
14 \\
7 \\
2 \\
2 \\
16 \\
18 \\
0 \\
0\end{array}$ \\
\hline Totals & 733 & & 90 \\
\hline
\end{tabular}

attempts to commit suicide. Head injuries were well assessed. The selection of cases for the short-stay ward appears to have been less good in cases of fracture and in the group of cases of laceration, abrasion, and contusion. This was more often due to an inaccurate appreciation of the length of stay necessary for a particular injury than to misdiagnosis. In retrospect it appears that about half the cases transferred in this group might initially have been recognized as unsuitable for the shortstay ward. The other cases developed complications which, though anticipated, were not inevitable. Thus, patients suitable for the short-stay ward were selected when first seen with about 95 per cent. accuracy. This assessment could be further improved by having fully experienced staff to see patients at all times of day and night. This is not, however, practicable.

\section{ANAlysis of Casualty WaRd Records}

The records for the complete year, 1961, were analysed. Patients were admitted throughout the day and night but were discharged usually in the morning. Accordingly, the figures given for the number of beds occupied refer to 9 a.m., and a patient's stay in the ward is the number of days on which he was occupying a bed at this time. Unfortunately one week's data on admissions was missing (11 to 17 July), and a few patients' record cards had not been completely filled in. This accounts for certain small discrepancies in the present results.

Table III gives the numbers of male and female patients admitted to the ward, classified by month, with the expected admissions assuming a constant Poisson distribution.

TABLE III

ADMISSIONS IN DIFFERENT MONTHS OF THE YEAR, BY SEX

\begin{tabular}{|c|c|c|c|c|c|}
\hline \multirow{2}{*}{ Month } & & \multicolumn{2}{|c|}{ Males } & \multicolumn{2}{|c|}{ Females } \\
\hline & & $\begin{array}{c}\text { No. } \\
\text { Observed }\end{array}$ & $\begin{array}{c}\text { No. } \\
\text { Expected }\end{array}$ & $\begin{array}{c}\text { No. } \\
\text { Observed }\end{array}$ & $\begin{array}{c}\text { No. } \\
\text { Expected }\end{array}$ \\
\hline 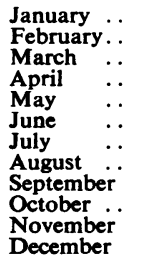 & $\begin{array}{l}\ldots \\
\ldots \\
\ldots \\
\cdots \\
\ldots \\
\cdots \\
\cdots \\
\cdots \\
\cdots\end{array}$ & $\begin{array}{l}46 \\
21 \\
20 \\
38 \\
40 \\
38 \\
24 \\
48 \\
41 \\
34 \\
38 \\
46\end{array}$ & $\begin{array}{l}37 \cdot 6 \\
33.9 \\
37.6 \\
36 \cdot 4 \\
37.6 \\
36 \cdot 4 \\
29 \cdot 1 \\
37 \cdot 6 \\
36 \cdot 4 \\
37.6 \\
36 \cdot 4 \\
37.6\end{array}$ & $\begin{array}{l}28 \\
21 \\
24 \\
32 \\
18 \\
24 \\
16 \\
24 \\
23 \\
21 \\
20 \\
31\end{array}$ & $\begin{array}{l}24 \cdot 4 \\
22 \cdot 1 \\
24 \cdot 4 \\
23 \cdot 6 \\
24 \cdot 4 \\
23 \cdot 6 \\
18 \cdot 9 \\
24 \cdot 4 \\
23 \cdot 6 \\
24 \cdot 4 \\
23 \cdot 6 \\
24 \cdot 4\end{array}$ \\
\hline
\end{tabular}

Table IV gives the total numbers of male and female patients admitted to the ward, classified by the day of the week.

TABLE IV

ADMISSIONS ON DIFFERENT DAYS OF THE WEEK, BY SEX

\begin{tabular}{|c|c|c|c|c|c|}
\hline \multicolumn{4}{|c|}{ Day of Week } & Males & Females \\
\hline $\begin{array}{l}\text { Sunday } \\
\text { Monday } \\
\text { Tuesday } \\
\text { Wednesday } \\
\text { Thursday } \\
\text { Friday } \\
\text { Saturday }\end{array}$ & $\begin{array}{l}\cdots \\
\cdots \\
\cdots \\
\cdots \\
\cdots\end{array}$ & $\begin{array}{l}\cdots \\
\cdots \\
\cdots \\
\cdots \\
\cdots\end{array}$ & $\begin{array}{l}\ddot{ } \\
\ddot{*} \\
\cdots \\
\cdots \\
\cdots\end{array}$ & $\begin{array}{l}52 \\
64 \\
50 \\
64 \\
61 \\
77 \\
66\end{array}$ & $\begin{array}{l}34 \\
49 \\
41 \\
50 \\
30 \\
45 \\
33\end{array}$ \\
\hline Average & $\ldots$ & $\ldots$ & . & $62 \cdot 0$ & $40 \cdot 3$ \\
\hline
\end{tabular}

Chi-squared tests on the separate columns of this Table, assuming the same Poisson distribution for each weekday, give $\chi^{2}{ }_{6}=8.0$ and $\chi_{6}^{2}=9.7$ respectively.

The data therefore afford very little basis (as indicated by the $\chi^{2}$ test) for distinguishing between the days of the week, for either males or females. 
The same applies to months of the year for female admission rates. Male admission rates, however, appear to be high in January, August, and December, and low in February and March.

Table $\mathrm{V}$ shows the frequency distributions of the number of admissions during one day, classified by sex, together with the expected numbers, assuming Poisson distributions.

TABLE V

FREQUENCY DISTRIBUTION OF NUMBER OF ADMISSIONS PER DAY, BY SEX

\begin{tabular}{|c|c|c|c|c|}
\hline \multirow{2}{*}{$\begin{array}{l}\text { Number of } \\
\text { Admissions } \\
\text { per Day }\end{array}$} & \multicolumn{2}{|c|}{ Males } & \multicolumn{2}{|c|}{ Females } \\
\hline & $\begin{array}{c}\text { No. } \\
\text { Observed }\end{array}$ & $\begin{array}{c}\text { No. } \\
\text { Expected }\end{array}$ & $\begin{array}{c}\text { No. } \\
\text { Observed }\end{array}$ & $\begin{array}{c}\text { No. } \\
\text { Expected }\end{array}$ \\
\hline $\begin{array}{l}0 \\
1 \\
2 \\
3 \\
4 \\
5 \\
6\end{array}$ & $\left.\begin{array}{r}114 \\
127 \\
64 \\
38 \\
11 \\
3 \\
1\end{array}\right\}$ & $\begin{array}{r}106 \cdot 5 \\
129 \cdot 1 \\
78 \cdot 3 \\
31 \cdot 6 \\
9 \cdot 6 \\
2 \cdot 9\end{array}$ & $\left.\begin{array}{r}164 \\
130 \\
44 \\
16 \\
4 \\
0\end{array}\right\}$ & $\begin{array}{r}162 \cdot 8 \\
128 \cdot 3 \\
50 \cdot 5 \\
13 \cdot 3 \\
3 \cdot 1\end{array}$ \\
\hline Average & $1 \cdot 21$ & & 0.79 & \\
\hline
\end{tabular}

Table VI gives the frequency distributions of duration of stay in the ward in 1961, classified by sex, together with the expected numbers assuming the geometric distribution. In none of the three distributions is there a significant discrepancy from the model, as indicated by the $\chi^{2}$ test.

TABLE VI

FREQUENCY DISTRIBUTION OF DURATION OF STAY IN THE WARD, BY SEX

\begin{tabular}{|c|c|c|c|c|c|c|}
\hline \multirow{2}{*}{$\begin{array}{c}\text { Duration } \\
\text { of Stay } \\
\text { (days) }\end{array}$} & \multicolumn{2}{|c|}{ Males } & \multicolumn{2}{|c|}{ Females } & \multicolumn{2}{|c|}{$\begin{array}{l}\text { Both Sexes } \\
\text { Combined }\end{array}$} \\
\hline & $\begin{array}{l}\text { No. Ob- } \\
\text { served }\end{array}$ & $\underset{\text { pected }}{\text { No. Ex- }}$ & $\begin{array}{l}\text { No. Ob- } \\
\text { served }\end{array}$ & $\begin{array}{c}\text { No. Ex- } \\
\text { pected }\end{array}$ & $\begin{array}{c}\text { No. Ob- } \\
\text { served }\end{array}$ & $\begin{array}{c}\text { No. Ex- } \\
\text { pected }\end{array}$ \\
\hline $\begin{array}{r}1 \\
2 \\
3 \\
4 \\
5 \\
6 \\
7 \\
8 \\
9 \\
10 \\
11\end{array}$ & $\begin{array}{r}254 \\
97 \\
46 \\
24 \\
5 \\
3 \\
4 \\
1 \\
0 \\
0 \\
0\end{array}$ & $\begin{array}{r}247 \cdot 5 \\
106 \cdot 4 \\
45 \cdot 7 \\
19 \cdot 6 \\
8 \cdot 4 \\
= \\
\overline{6 \cdot 4} \\
= \\
-\end{array}$ & $\begin{array}{r}168 \\
61 \\
37 \\
11 \\
1 \\
0 \\
2 \\
1 \\
0 \\
0 \\
1\end{array}$ & $\begin{array}{c}164 \cdot 7 \\
68 \cdot 5 \\
28 \cdot 5 \\
11 \cdot 9 \\
= \\
= \\
8 \cdot 4 \\
= \\
-\end{array}$ & $\begin{array}{r}422 \\
158 \\
83 \\
35 \\
6 \\
3 \\
6 \\
2 \\
0 \\
0 \\
1\end{array}$ & $\begin{array}{c}412 \cdot 1 \\
175 \cdot 0 \\
74 \cdot 3 \\
31 \cdot 5 \\
13 \cdot 4 \\
= \\
9 \cdot 7 \\
= \\
=\end{array}$ \\
\hline Average & $1 \cdot 75$ & - & $1 \cdot 71$ & - & $1 \cdot 74$ & - \\
\hline
\end{tabular}

Table VII gives the frequency distribution of number of beds occupied in the ward, classified by sex. These distributions are compared with the Poisson distributions predicted from the theory developed in the next section. It is clear that the fit is excellent. (No $\chi^{2}$ test has been carried out as these observations are not independent.)

TABLE VII

NUMBER OF DAYS IN 1961 ON WHICH THE STATED NUMBER OF BEDS WERE OCCUPIED

\begin{tabular}{c|c|c|c|c}
\hline \multirow{2}{*}{$\begin{array}{c}\text { No. of } \\
\text { Beds } \\
\text { Occupied }\end{array}$} & \multicolumn{2}{|c|}{ Males } & \multicolumn{2}{c}{ Females } \\
\cline { 2 - 5 } & $\begin{array}{c}\text { No. } \\
\text { Observed }\end{array}$ & $\begin{array}{c}\text { No. } \\
\text { Predicted }\end{array}$ & $\begin{array}{c}\text { No. } \\
\text { Observed }\end{array}$ & $\begin{array}{c}\text { No. } \\
\text { Predicted }\end{array}$ \\
\hline 0 & 48 & 42.2 & 88 & $91 \cdot 5$ \\
1 & 76 & 89.5 & 122 & 123.3 \\
2 & 101 & 94.9 & 84 & 83.0 \\
3 & 71 & 67.1 & 43 & 37.3 \\
4 & 32 & 35.6 & 12 & 12.6 \\
5 & 17 & 15.1 & 3 & 3.4 \\
6 & 6 & 5.3 & 0 & 0.8 \\
7 & 1 & 1.6 & 0 & 0.1 \\
8 & 0 & 0.7 & 0 & 0.0 \\
\hline
\end{tabular}

Number of Beds ReQuired

According to Table $\mathrm{V}$ the numbers of male and female patients admitted to the ward per day both follow a Poisson distribution. That is, the probability that $j$ male (female) patients are admitted in a day is given by:

$$
e^{-m} m^{j} / j !
$$

where $m$ is the mean male (female) admission rate per day. This implies further that the total number of admissions per day also follows a Poisson distribution, with mean admission rate the sum of the separate mean admission rates.

The duration of stay in the ward (in days) follows the same geometric distribution for male and female patients. That is, the probability that a patient stays in the ward for $k$ days is given by:

$$
p(1-p)^{k-1}, \quad k \geqslant 1
$$

where $1 / p$ is the mean duration of stay. This distribution implies that the mean number of patients staying $k$ days is a constant proportion $(1-p)$ of the mean number of patients staying $(k-1)$ days.

These two results imply (see Appendix) that the number of beds occupied follows a Poisson distribution with mean equal to the average number of admissions per day multiplied by the average duration of stay. It is important to note (see Appendix) that this result depends only on the fact that the number of admissions per day follows a Poisson distribution, that is the distribution of the duration of stay (as distinct from its mean) plays no part in the distribution of the number of beds occupied. The number of beds actually occupied does in fact follow this distribution (Table VII). 
The Figure shows, for a given mean number of beds occupied $b$, the proportion of days on which $n$ beds are adequate; $b$ is plotted against $P(n, b)$, where:

$$
P(n, b)=\sum_{i=0}^{n} e^{b} b^{i} / i !
$$

For example, if the mean admission rate is two patients per day and their mean duration of stay is 2 days, then seven beds will be adequate 95 per cent. of the time and eight beds 98 per cent. of the time. But the sexes must be considered separately. Suppose on average one man and one woman are admitted each day, and their average duration of stay is 2 days then eight beds will now be adequate only 90 per cent. of the time, unless some beds are available for use by either sex. Similarly, for given data one can calculate how many beds should be available for use by either sex so that the smallest possible number of beds will suffice.

\section{Discussion}

Recommendations have been made in the past few years in regard to the improvement of Casualty Services (British Orthopaedic Association, 1959; Accident Services Review Committee of the B.M.A., 1961 ; Central Health Services Committee, 1962).
It has been recommended that what is now the Casualty Department shall in future be known as the Accident and Emergency Department. This emphasizes that such a Department is responsible for treatment of emergencies other than accidents. It is accepted that serious injuries and major nontraumatic emergencies should be treated in the appropriate major units. However, we have found that the work of these wards is significantly lessened by the provision of a short-stay ward in the Casualty Department. Table II gives the type of case admitted to the short-stay ward. There are three large groups: fractures and lacerations, head injuries, and drug overdose.

A short-stay ward is particularly useful in the initial surveillance of many so-called minor fractures after application of plaster. A large number of head injuries require observation for fear of complications which so seldom occur that it is unreasonable to admit all these cases to the neurosurgical wards. Table I shows that the receiving teams in major accident wards in Aberdeen are treating about 500 cases a year. If they were to take in addition all the traumatic cases at present kept in the short-stay ward, they would have to treat almost double this number. A good example of the use of the ward for non-traumatic emergencies is the increasing number of poisonings, nearly all deliberate. In such cases the

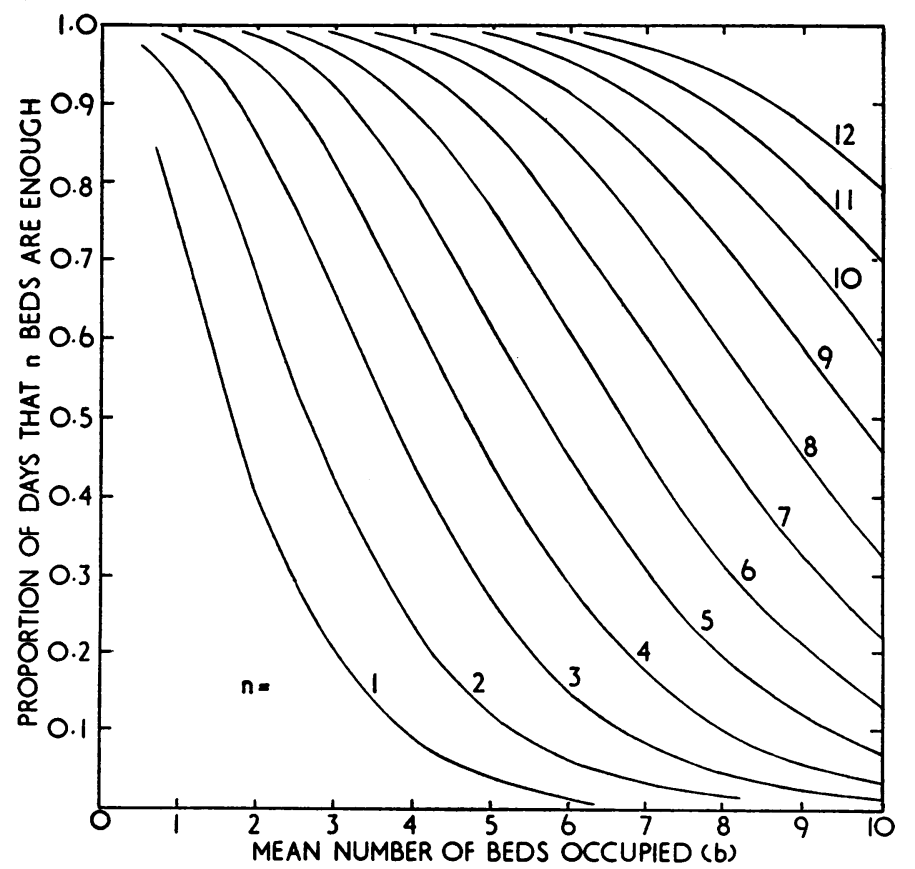

FIG.-Days on which a number of beds is adequate for a given mean number of beds occupied. 
physical illness caused by the intoxication rarely lasts more than 2 days. A close liaison with the Department of Mental Health ensures no loss of time in instituting psychiatric treatment.

It is demonstrated in Table VII that the number of beds actually occupied in the short-stay ward follows a Poisson distribution. This has practical implications. Fluctuations in the number of beds required are large, and sufficient beds must be provided to make reasonable allowance for these. If there are enough beds to allow for a fluctuating demand 98 per cent. of the time, the average proportion of beds occupied will be only 35 per cent. This indicates that the usual standards of bed occupancy cannot be applied to this type of ward to which emergencies only are admitted. The figure of 35 per cent. therefore does not imply that we had more beds than we required. As Table VII shows, any reduction in the available beds would have resulted in inability to cope with demand on a significant proportion of days in the year.

Newell (1954) drew attention to the problem of emergency admissions of all kinds to hospitals, and he found that these admissions followed a Poisson distribution. It is reasonable to assume therefore that the admissions to the recently proposed Accident and Emergency Units will also be of this type; in this case our results show that the distribution of the number of beds occupied in such a unit will have a Poisson distribution with mean equal to the mean admission rate per day multiplied by the mean duration of stay. This has important implications for the planning of the accommodation and facilities for these units.

\section{SUMmaRY}

(1) The work of a short-stay Casualty ward is described for the year 1961 .

(2) The number of admissions to the ward, and the number of beds occupied, fluctuate from day to day. However, these fluctuations can be simply and accurately described in terms of the Poisson distribution. This fact allows one to estimate, from the average number of beds occupied, the number actually required to allow for random fluctuations in demand (Figure).

(3) The mathematical model is given in an appendix.

\section{REFERENCES}

Accident Services Review Committee (Chairman: H. Osmond-Clarke) (1961). "Accident Services of Great Britain and Ireland: Interim Report". B.M.A., London

British Orthopaedic Association (1959). "Memorandum on Accident Services", J. Bone Jt. Surg., 41B, 458.

Central Health Services Council: Standing Medical Ad-O visory Committee (1962). "Accident and Emergency Services: Report of the Sub-committee". H.M.S.O., London.

Newell, D. J. (1954). Brit. J. prev. soc. Med., 8, 77.

\section{APPENDIX}

We suppose (1) that there is an infinite number of beds available; (2) that the probability that the duration of stay of a patient is $j$ days is $p_{j}$, independent of any other aspect of the system; and (3) that the number of admissions on any particular day follows a Poisson distribution, mean $m$, independent of the number of admissions on previous days and also independent of any other aspect of the system.

We consider the system on a particular morning at 9 a.m., after it has been in operation for a "long" time ("long" is related to the right hand tail of the distribution of duration of stay; in the case of the short-stay casualty ward, a "long" time is only a matter of about 2 weeks). Let $b$ and $b_{j}$ be the number of beds occupied by all patients and patients who stay $j$ days in all respectively. Then:

$$
b_{j}=\sum_{i=1}^{j} b_{j}^{i}
$$

where $b_{j} j$ is the number of these $b_{j}$ patients who arrived $i$ days previously. The $b_{j}{ }_{j}$ all have the same Poisson distribution

$$
\operatorname{Prob}\left(b_{j}=k\right)=e^{-m p_{j}}\left[m p_{j}\right]^{k} / k \text { ! }
$$

since the proportion of the arriving patients who stay $j$ days is $p_{j}$. Thus $b_{j}$ is distributed as a Poisson variable with mean $j m p_{j}$ since the sum of independent Poisson distributions is also a Poisson distribution. Furthermore,

$$
b=\sum_{j=1}^{\infty} b_{j}
$$

has therefore a Poisson distribution with mean

$$
\sum_{j=1}^{\infty} j m p_{j}=m \times d
$$

where $d$ is the mean duration of stay.

(This method of proof was suggested to one of us (MCP) by Prof. D. G. Kendall. A direct proof for the case of a geometric distribution of duration of stay had previously been obtained but the above proof is, of course, much more general.) 